\title{
Genetic parameters for female fertility in Nordic Holstein and Red Cattle dairy breeds
}

\author{
Kirsi Muuttoranta, ${ }^{1}$ Anna-Maria Tyrisevä, ${ }^{1}$ Esa A. Mäntysaari, ${ }^{1}$ Jukka Pösö, ${ }^{2}$ Gert Pedersen Aamand, ${ }^{3}$ \\ and Martin H. Lidauer ${ }^{1 *}$ \\ ${ }^{1}$ Natural Resources Institute Finland (Luke), FI-31600 Jokioinen, Finland \\ ${ }^{2}$ Faba Co-op, PO Box 40, FI-01301 Vantaa, Finland \\ ${ }^{3}$ Nordic Cattle Genetic Evaluation, DK-8200 Aarhus, Denmark
}

\section{ABSTRACT}

Genetic evaluation of female fertility in Danish, Finnish, and Swedish dairy cows was updated in 2015 to multiple-trait animal model evaluation, where heifer and cow fertility up to third parity are considered as separate traits. A model for conception rate was also developed, which required variance component estimation for Nordic Holstein and Nordic Red Dairy Cattle. We used a multiple-trait multiple-lactation sire model to determine variance components for interval from calving to first insemination, length of service period, and conception rate. Monte Carlo Expectation Maximization REML allowed estimation of all 11 traits simultaneously. Study data were sampled from Swedish Holstein $(\mathrm{n}=140,040)$ and Red Dairy Cattle $(\mathrm{n}=101,315)$ heifers and cows. Conception rate observations are binomial observations with various numbers of failures preceding an observation of success. Using a simulation study, we confirmed that including a service number effect into the conception rate model allowed us to model the change in expectation of successful AI with increasing number of services. Heifers outperformed cows in all fertility traits according to the phenotypic means in the records. Heritabilities for the traits varied from 3 to $7 \%$ for interval from calving to first insemination, from 1 to $5 \%$ for length of service period, and from 1 to $3 \%$ for conception rate. Genetic correlations within traits (i.e., between parities) were favorable, ranging from moderate to high; genetic correlations between heifer and cow traits were lower than between cow traits in different parities. Lowest genetic correlations between traits were for interval from calving to first insemination and conception rate, intermediate for interval from calving

Received October 16, 2018.

Accepted April 30, 2019.

*Corresponding author: martin.lidauer@luke.fi to first insemination and length of service period, and highest for length of service period and conception rate. The variance components estimated in this study have been used in Nordic fertility breeding value evaluations since 2016.

Key words: dairy cow, fertility, conception rate, heritability, variance components

\section{INTRODUCTION}

Deterioration of female fertility in dairy cows has shifted breeding goals toward those adopted in the Nordic countries as early as the 1960s (Philipsson and Lindhé, 2003). Today, female fertility is a standard component in modern dairy cattle breeding programs. Two-thirds of the countries participating in the international genetic evaluation of dairy sires carry out national genetic evaluations of female fertility (Interbull, 2019a). Compared with production traits, female fertility is a complex breeding goal affected by several factors and with no perfect measure to describe it exhaustively (Berry et al., 2014). The fertility traits most commonly used in the international genetic evaluation of dairy sires are grouped into 5 different categories: (T1) maiden heifer's ability to conceive, (T2) lactating cow's ability to resume cyclicity after calving, (T3) lactating cow's ability to conceive expressed as a rate trait, (T4) lactating cow's ability to conceive expressed as an interval trait, and (T5) lactating cow's measurements of the interval trait calving to conception (Interbull, 2019b). The participating countries generally use the following traits: interval from calving to first insemination (ICF), nonreturn rate (NRR), conception rate (CR), interval from first to last insemination (IFL), and days open (DO), which belong in categories T2, T1 and T3, T4, and T5, respectively (Interbull, 2019b). Because all these traits typically have low heritability, they have to be assigned a significant weight in breeding programs to enhance genetic gain (Pryce and Veerkamp, 2001; Wall et al., 2003; Berry et al., 2014). Genetic prog- 
ress can be improved by genomic evaluations of female fertility (e.g., Aguilar et al., 2011; Matilainen et al., 2018), which enable more precise prediction of breeding values at the time of selection. Nevertheless, accurate modeling of fertility traits is crucial, and accounting for correlations between the different fertility traits is important to capture the various aspects of fertility. Studies have, in fact, reported wide variation in genetic correlations between heifer and cow fertility traits, varying from low to high (Liu et al., 2008; Tiezzi et al., 2012). Correlations below unity provide evidence that genetic control of heifer and cow fertility traits differs at least to some degree, which should be taken into account when designing breeding programs (Pryce et al., 2004; Tiezzi et al., 2012; Wathes et al., 2014).

The complexity and low heritability of female fertility are not the only challenges faced in genetic improvement efforts. In addition, the traits that describe fertility are primarily either discrete traits (e.g., NRR, $\mathrm{CR}$ ) or interval traits with skewed (e.g., ICF, DO) or zero-inflated distributions (e.g., IFL) (AndersenRanberg et al., 2005; Chang et al., 2006; Berry et al., 2014). Although threshold models would theoretically be most correct for discrete traits, linear models have been widely used, as noted in the review by Pryce and Veerkamp (2001). The reason is that until now, the use of threshold models in multiple-trait settings of large data sets has not been feasible in cases where computing time is a critical concern, as is typical for routine genetic evaluations (e.g., Kuhn et al., 2006; Matilainen et al., 2009; Koeck et al., 2010). Multiple-trait settings are, however, crucial to describe the various biological aspects of female fertility. Yet, if the data comprise a large number of observations and the incidence of a binary trait is intermediate and fairly homogeneous across the fixed effects, then linear models should provide results similar to those of threshold models (e.g., Kadarmideen et al., 2003; Andersen-Ranberg et al., 2005; Koeck et al., 2010; Liu et al., 2017). Approximately intermediate incidence applies to CR in many populations (e.g., Kadarmideen et al., 2003; Barbat et al., 2010; Liu et al., 2017).

Female fertility traits also often include censored observations. Females that are culled with unknown pregnancy status or that have records in progress at the time of data extraction are reasons for censoring. In a study on Norwegian Red cattle by Chang et al. (2006), for example, the proportion of censored observations was $21 \%$. Although the increasing use of pregnancy monitoring has improved the situation, there are still many cases where censored observations must be taken into account. Otherwise, females with the best fertility will be overrepresented in the data sets, and those with the poorest fertility underrepresented, creating bias in evaluations. The most appealing solution is to use censored models, as shown by Chang et al. (2006). However, as noted above, this is not an easy task in the current multiple-trait setting with large data sets. Denmark, Finland, and Sweden have adopted a different strategy, largely made possible by the integrated databases of milk recording, calving information, and $\mathrm{AI}$ and veterinary services in the Nordic countries. The databases are owned by dairy farmers' cooperatives and comprise records of the majority of herds and cows in the Nordic countries (Philipsson and Lindhé, 2003; ICAR, 2019). These data are used comprehensively. The data also contain information on the results of pregnancy monitoring, and so the fertility records of all females with positive results can be used directly. Penalties are added for other censored observations, to account for uncertainty of the final phenotype of the censored animals.

The joint Nordic (Denmark, Finland, and Sweden) evaluation for female fertility includes 6 different fertility traits, the most important of which are ICF, IFL, and CR. Within each of these 3 traits, observations for maiden heifers and for the first 3 parities of cows are considered as different traits (denoted in this paper as ICF0, ICF1, ICF2, ICF3, and so on for each trait). The genetic evaluation was updated in 2015 from a multiple-trait sire model (Fogh et al., 2003) to a multiple-trait animal model (Muuttoranta et al., 2015; Tyrisevä et al., 2017), which enables better modeling of the environment and use of correlated information. Upgrading to the animal model was also a prerequisite for development of single-step genomic evaluations for fertility traits (Matilainen et al., 2018). To build these new evaluations, we needed to estimate multipletrait variance components. The estimation of variance components is quite often restricted, for computational reasons, to estimation of parameter subsets instead of allowing all parameters to be determined simultaneously (e.g., Liu et al., 2008). This is not optimal, because obtaining a positive definite multiple-trait matrix requires application of a bending procedure (Hayes and Hill, 1981). We applied the procedure proposed by Matilainen et al. (2012), who implemented a Monte Carlo Expectation Maximization REML (MC EM-REML) algorithm (García-Cortés et al., 1992), by which all multiple-trait variance components could be estimated in a single analysis.

The objective of this study was to estimate variance components for ICF, IFL, and CR for Nordic Holstein (HOL) and Nordic Red Dairy Cattle (RDC) by applying MC EM-REML, which allowed estimation of all of the 11 fertility traits simultaneously. 


\section{MATERIALS AND METHODS}

\section{Data Sampling for Variance Component Estimation}

Data for this study were obtained from Nordic Cattle Genetic Evaluation (NAV), the organization that runs the breeding evaluations in Denmark, Finland, and Sweden. Sampling of data followed the same procedure applied by Lidauer et al. (2015) in variance component estimation for NAV evaluation of yield traits. Their work suggested that sampling from Swedish herds would produce the best representative data for all 3 NAV countries and breeds. The data from the Swedish official milk recording scheme contained 6,942,842 and 8,474,052 fertility records of the HOL and RDC breeds, respectively. Average herd size was 40 cows for HOL and 32 cows for RDC.

Fertility data were restricted to cows and heifers born after 1994 that had calved before 2012, were daughters of AI bulls, and had not undergone embryo transfers either as a recipient or as a donor. Heifers younger than $270 \mathrm{~d}$ and older than $900 \mathrm{~d}$ at first insemination were excluded. Age at first calving was restricted to between 550 and 1,100 d. Furthermore, we excluded heifers older than $1,240 \mathrm{~d}$ that had not calved or been culled, as well as cows with more than 2 years from the last calving. Females changing herd during a service period were excluded for that parity. Possible double inseminations during a heat were considered as 2 separate inseminations, if the interval between services was more than $5 \mathrm{~d}$.

All herds with less than 12 (HOL) or 8 (RDC) firstcalvers annually were discarded to ensure tolerable contemporary group sizes. Out of the remaining 746 HOL and 429 RDC herds, we randomly sampled 400 herds in both breeds. After all edits, the HOL data set contained 2,946 sires having 140,040 daughters with records, and the RDC data set 1,882 sires having 101,315 daughters with records.

\section{Analyzed Traits}

The analyses comprised the 3 fertility traits ICF, IFL, and CR, for which observations from the first 3 parities (indicated by 1, 2, and 3) were considered as different traits. For IFL and CR, observations from maiden heifers (indicated by IFL0 and CR0) were also regarded as separate traits. Hence, the total number of fertility traits in the analyses was 11.

Interval from Calving to First Insemination. The ICF is measured in days and describes a cow's ability to resume cyclicity after calving and to show estrus. Among the included fertility traits, its distribution is closest to normality. We edited the observations according to NAV's editing rules for female fertility evaluation. If an ICF observation was outside the boundaries of 20 to $230 \mathrm{~d}$, it was excluded. The upper limit of the distribution was further trimmed by setting the maximum value to $180 \mathrm{~d}$. Thus, all values from 181 to 230 were set to 180. Further, we followed NAV's editing rules for all records ending with culling or records still in progress. We only used observations for such cases if the time between previous calving and data extraction was more than $150 \mathrm{~d}$; otherwise, the observations were excluded.

Interval from First to Last Service. The IFL is measured in days and describes the ability of the female to show estrus and to conceive, and the ability of the embryo to survive. Because every unsuccessful service prolongs this trait by another estrus cycle or by multiple cycles if the cow fails to show heat, IFL observations will give rise to a multi-peak distribution. If the first service was successful, its phenotypic value was 0 . If IFL was $365 \mathrm{~d}$ or more, the observation was excluded from the analysis. Records ending with culling or still in progress were edited according to NAV's editing rules for female fertility evaluation. If a female had a positive pregnancy control result and the first service was more than $56 \mathrm{~d}$ from data extraction, the IFL value was accepted as such. If a female had no positive pregnancy control result, the IFL was extended. Extension of IFL is a complex process by which records are classified based on pregnancy control results (negative, not known) and on the distance between data extraction or culling date and the first and last service dates. If a record was still in progress and data extraction was less than or equal to $56 \mathrm{~d}$ from first service, then the IFL observation was excluded. Otherwise the observation was given a class-specific penalty by utilizing country-, parity-, and breed-specific means for IFL. The outmost boundary of extended phenotypes was set to $230 \mathrm{~d}$ to normalize the distribution. Further, if there were more than $91 \mathrm{~d}$ between 2 consecutive services of a heifer, that IFL record was deleted, to prevent poor heat detection from being misinterpreted as poor fertility. In the Nordic countries, heat detection of heifers is typically more accurate during the indoor season than in the summer season when heifers are on pasture. Finally, we edited the observations that were outside the acceptable boundaries for gestation length, from 260 up to 302. If gestation length was too short, the IFL observation was deleted. If it was too long, IFL was recalculated according to 2 consecutive calving dates, considering an average gestation length of $281 \mathrm{~d}$ for both breeds.

Conception Rate. Each service event was considered as a CR observation. In line with NAV's editing 
rules for female fertility evaluation, phenotypic values were determined by a complex process using several information sources: services, pregnancy monitoring information, calvings, information on live sales, and cullings. All the available data were used to define the phenotypic value of a service as either a success (1) or a failure (0). We excluded all CR observations occurring $150 \mathrm{~d}$ before the data extraction date, to minimize the effect of right-hand censoring. By following this strategy, we found only a few records in progress, and set the $\mathrm{CR}$ observation for those records to the expected value of 0.7 , the average NRR in heifers. The rationale behind this was that if a female had no events for $150 \mathrm{~d}$ before data extraction, she was very probably pregnant and had not yet calved. If a female was culled, the last record was set to successful only if it had a positive pregnancy control result; otherwise it was set to 0 . As for IFL, the last service before calving had to fit within the length of the gestation period of 260 to $302 \mathrm{~d}$. If it did not, previous services were checked iteratively, and the one fitting the accepted gestation length was considered successful, whereas the other services were set to failures. At maximum, the first 10 services per a service period of a female were included in the data. To illustrate, a female that conceived from the fourth service in the service period would have 4 records, with observations $0,0,0$, and 1 .

The final data are presented by traits and breeds in Table 1. The number of observations was highest in first-parity cows and decreased toward the third parity, indicating culling of cows for age. Interval traits had 1 observation at maximum per female per parity, whereas for $\mathrm{CR}$, the number of observations was equal to the total number of services.

\section{Validating the Modeling of Repeated CR Observations}

To validate the appropriateness of the model for CR, we carried out a simulation study. Modeling the outcome of repeated services of a cow using a repeatability model is challenging, because success in conceiving may be preceded by failures, and so the model's expectation of success decreases with increasing number of services. Hence, it can be assumed that under such circumstances the model is likely to attribute success largely to an improved environment. If $\mathrm{CR}$ is not modeled properly, the estimated environmental trend is likely to be biased, because the expectation of success from repeated services reduces over time. To address this issue, we simulated replicates of the data sets based on a subset of HOL data for variance component estimation. The subset comprised 119,684 first-parity cows with CR observations.

First, we simulated a true underlying animal model breeding value for all animals based on the pedigree structure. Then, observations were simulated for all cows having records in the original real data. Residual terms were, therefore, repeatedly simulated on the underlying scale and added to the cow's breeding value, to build a series of phenotypic observations. Phenotypic values were generated until the first phenotypic value exceeded the threshold for success. The maximum number of observations per cow was set to 10 , and the probability for successful insemination to 0.6. If the sampled record was higher than the threshold, CR was set to 1 on the observed scale; otherwise, to 0 . For the simulation, the underlying phenotypic variance was set to 0.25 and heritability to 0.1 , corresponding to a heri-

Table 1. Descriptive statistics of the data used for variance component estimation including number of observations (N), phenotype mean (Mean), and standard deviation (SD) in Nordic Holstein (HOL) and Nordic Red Dairy Cattle (RDC)

\begin{tabular}{|c|c|c|c|c|c|c|}
\hline \multirow[b]{2}{*}{ Trait $^{1}$} & \multicolumn{2}{|c|}{$\mathrm{N}$} & \multicolumn{2}{|c|}{ Mean } & \multicolumn{2}{|c|}{ SD } \\
\hline & HOL & $\mathrm{RDC}$ & HOL & $\mathrm{RDC}$ & HOL & $\mathrm{RDC}$ \\
\hline ICF1 & 113,765 & 83,669 & 90.5 & 83.3 & 35.3 & 29.9 \\
\hline ICF2 & 79,797 & 60,004 & 89.3 & 80.6 & 34.8 & 28.9 \\
\hline ICF3 & 44,442 & 34,723 & 89.6 & 80.8 & 34.8 & 29.0 \\
\hline IFL0 & 102,326 & 80,375 & 18.1 & 15.7 & 35.7 & 31.3 \\
\hline IFL1 & 113,169 & 83,463 & 48.1 & 40.7 & 66.1 & 58.4 \\
\hline IFL2 & 79,452 & 59,901 & 53.3 & 41.4 & 67.4 & 57.9 \\
\hline IFL3 & 44,294 & 34,673 & 52.7 & 42.8 & 66.2 & 58.6 \\
\hline CR0 & 176,286 & 136,290 & 0.65 & 0.67 & 0.48 & 0.47 \\
\hline CR1 & 225,741 & 159,759 & 0.46 & 0.48 & 0.50 & 0.50 \\
\hline CR2 & 162,258 & 112,392 & 0.42 & 0.46 & 0.49 & 0.50 \\
\hline CR3 & 89,061 & 65,087 & 0.42 & 0.45 & 0.49 & 0.50 \\
\hline
\end{tabular}

${ }^{1}$ Traits: ICF $=$ interval from calving to first insemination, IFL $=$ interval from first insemination to last insemination, $\mathrm{CR}=$ conception rate: $0=$ heifers, $1=$ first, $2=$ second, and $3=$ third parity. 
tability of 0.063 on the observed scale (Gianola, 1979). To ensure a stable environmental trend, the effects of herd $\times$ year and insemination year $\times$ month were set to 0 , and no permanent environment was simulated. In total, we simulated 5 data replicates.

To study the effect of the different expectations related to the first through the tenth service, we first included the effect of service number (the ordinal number of each service event during a service period) into the model and then excluded it. All data replicates were analyzed both with the animal model and with the sire model. Variance component estimation was carried out using the REML procedure in the DMU software package (Madsen and Jensen, 2012). The applied model was as follows:

$$
\widetilde{C R}_{i j k l m}=\hat{h}_{i}+\hat{t}_{j}+\hat{n}_{k}+\hat{p}_{l}+\hat{u}_{m}+\hat{e}_{i j k l m},
$$

where $\widetilde{C R}_{i j k l m}$ is the $k$ th simulated observation for an animal $m, \hat{h}_{i}$ is the herd $\times$ year fixed effect, $\hat{t}_{j}$ is the insemination year $\times$ month fixed effect, $\hat{n}_{k}$ is the service number fixed effect, $\hat{p}_{l}$ is the random permanent environment effect, $\hat{u}_{m}$ is the random additive genetic effect (either animal effect $\hat{a}_{m}$ or sire effect $\hat{s}_{m}$ ), and $\hat{e}_{i j k l m}$ is the random residual. In the alternative model, the fixed effect of service number $\hat{n}_{k}$ was excluded. The estimated variance components from each data replicate $\times$ model alternative analysis $s$ were used to calculate the heritability and repeatability on the observed scale, $h_{s}^{2}=\frac{\hat{\sigma}_{u}^{2}}{\hat{\sigma}_{u}^{2}+\hat{\sigma}_{p}^{2}+\hat{\sigma}_{e}^{2}}$ and $r_{s}=\frac{\hat{\sigma}_{u}^{2}+\hat{\sigma}_{p}^{2}}{\hat{\sigma}_{u}^{2}+\hat{\sigma}_{p}^{2}+\hat{\sigma}_{e}^{2}}$, respectively. For the animal model analyses $\hat{\sigma}_{u}^{2}$ was equal to $\hat{\sigma}_{a}^{2}$, and for the sire model analyses $\hat{\sigma}_{u}^{2}$ was equal to $4 \hat{\sigma}_{s}^{2}$ and the value $3 \hat{\sigma}_{s}^{2}$ was subtracted from $\hat{\sigma}_{e}^{2}$.

To test whether excluding the service number effect would cause a bias in the estimated genetic trend, we estimated breeding values (BV) for all 5 data sample replicates with both animal models by applying the same set of variance components, the average of estimated variance components obtained using the animal model with the service number effect included. Next, we fitted a weighted linear regression of the cows' year of birth on the BV means of the birth year classes, and applied a $t$-test statistics to assess bias.

\section{Variance Component Estimation}

Variance and covariance components for all 11 traits were estimated simultaneously with MC EM-REML (Matilainen et al., 2012). We used a linear model to allow multiple-trait analysis, although a threshold model might have been theoretically superior for analyzing
CR. The same multiple-trait multiple-lactation repeatability sire model was fitted for both breeds. The model was the same for all 11 traits, and included the following effects:

$y_{i j k l m n o}=h y_{i}+y m_{j}+i a g e_{k}+i^{t h} A I_{l}+p e_{m}+\operatorname{sire}_{n}+e_{i j k l m n o}$,

where $y_{i j k l m n o}$ is an individual observation, $h y_{i}$ is the herd $\times$ birth year for heifer traits, or herd $\times$ actual calving year for cow traits, $y m_{j}$ is the year $\times$ month of calving for ICF or year $\times$ month of insemination for IFL and CR, iage is the age at first insemination in heifers, $i^{\text {th }} A I_{l}$ is the service number of an animal during a service period (for CR only), $p e_{m}$ is the random genetic effect of the permanent environment of an animal, sire $_{n}$ is the random genetic effect of sire, and $e_{i j k l m n o}$ is the random residual effect. Relationships between sires were accounted for by setting up a sire-maternal grandsire numerator relationship matrix for the sire effect.

Variance components were estimated by applying the MC EM-REML implementation in MiX99 software (MiX99 Development Team, 2017). Due to the algorithm implementations in MiX99, estimation of residual variance and covariance components for this particular model required that a permanent environmental effect had to be modeled for all traits. To avoid overparameterization for the traits without repeated observations, we fixed the residual variances of interval traits to be $2 \%$ of the phenotypic variance in the MC EM-REML analyses.

\section{RESULTS AND DISCUSSION}

\section{Fertility Traits on the Phenotypic Level}

Heifers had better fertility in terms of phenotypic means compared with cows in all the studied traits, whereas we found less variation among the cow traits. Although heifer fertility traits are considered phenotypically different from cow fertility traits, they are highly correlated (Pryce et al., 2004; Norman et al., 2009; Gredler and Schnyder, 2013). The decline of fertility with age was also seen in the mean values of cow traits, which decreased gradually with increasing number of parities. This is a common phenomenon reported in several studies (Boichard and Manfredi, 1994; Norman et al., 2009; de Haer et al., 2013). Breed-wise differences were clear. The RDC outperformed HOL in all traits and parities, although the differences in the means of interval traits were greater than for CR traits.

Drawing comparisons between the phenotypic means reported in various studies is quite challenging, because data editing, trait definitions, and management 
Table 2. Averages of estimated parameters from 5 data replicates; for calculation of heritability, the variance components estimated under the sire model were converted to animal model estimates

\begin{tabular}{lcccccc}
\hline & \multicolumn{5}{c}{ Estimates $^{1}$} \\
\cline { 2 - 6 } Estimation model & $\operatorname{Var}(\mathrm{a})$ & $\operatorname{Var}(\mathrm{pe})$ & $\operatorname{Var}(\mathrm{e})$ & $\operatorname{Var}(\mathrm{p})$ & $\mathrm{h}^{2}$ & $\mathrm{r}$ \\
\hline Sire model & & & & & & \\
SN included & & & & & & \\
SN excluded & 0.0045 & 0.056 & 0.190 & 0.250 & 0.071 & 0.241 \\
Animal model & 0.0036 & 0.007 & 0.231 & 0.241 & 0.060 & 0.042 \\
SN included & 0.0179 & 0.042 & 0.190 & 0.250 & 0.071 & 0.240 \\
SN excluded & 0.0111 & 0.000 & 0.229 & 0.241 & 0.046 & 0.046 \\
\hline
\end{tabular}

${ }^{1}$ Estimates: $\operatorname{Var}(\mathrm{a})=$ additive genetic, $\operatorname{Var}(\mathrm{pe})=$ permanent environmental, $\operatorname{Var}(\mathrm{e})=$ residual, and $\operatorname{Var}(\mathrm{p})=$ phenotypic variance; $h^{2}=$ heritability, and $\mathrm{r}=$ repeatability.

${ }^{2} \mathrm{SN}=$ fixed effect of service number in the model.

practices (e.g., use of voluntary waiting period and estrus synchronization) may vary considerably between countries, and even within countries among breeds and subpopulations. Comparisons can, therefore, be only suggestive. Yet, according to various reports, Nordic RDC not only outperformed Nordic HOL but also ranked among the best when compared with other dairy breeds. On the other hand, Nordic HOL ranked differently in different fertility traits. The ICF means for Nordic HOL were among the longest, whereas the IFL and CR means of heifers were among the best (Boichard and Manfredi, 1994; Roxström et al., 2001; Kuhn et al., 2006; Norman et al., 2009; Barbat et al., 2010; Aguilar et al., 2011; Tiezzi et al., 2011; Tiezzi et al., 2012; Gredler and Schnyder, 2013; de Haer et al., 2013; Pritchard et al., 2013; Liu et al., 2017).

\section{Validating the Modeling of Repeated CR Observations}

We conducted the simulation study because identifying a proper model for repeated CR observations was not an obvious choice. Variance component analyses under both the sire and animal models yielded on average the same heritability and repeatability estimates when a time-dependent effect (service number) was included into the model (Table 2). Heritabilities were on average 0.8 percentage points higher than expected $(6.3 \%)$. Adding the service number as a fixed effect into the model yielded year $\times$ month of insemination fixed effect estimates that did not show a time trend (Figure 1) and, thus, were in agreement with the simulated estimates. In contrast, when the analyses were carried out with the models without the service number effect, the estimated heritabilities and repeatabilities were lower, and the estimates for year $\times$ month of insemination fixed effects exhibited an upward bias (Figure 1). The genetic trend, consequently, became downward biased
(Figure 2). When the animal model included the fixed effect of service number, the average of the linear regression coefficients of birth year on yearly BV means was $-0.23 \%$ of genetic standard deviation, which did not differ significantly from $0(t$-value $=0.67)$. On the other hand, when the service number fixed effect was excluded from the animal model, the average of the regression coefficients was $-0.92 \%$ of genetic standard deviation, which was significantly different from $0(t-$ value $=2.93, P<0.05)$. Testing the difference between the regression coefficients from the 2 models with a paired $t$-test resulted in a $t$-value of $18.90(P<0.001)$. Variance component estimations under both models produced similar results. However, animal model analyses without the service number fixed effect exhibited slow convergence behavior.

In other studies, possible bias in estimates from CR models has been avoided by either adding a timedependent effect or by analyzing the $\mathrm{CR}$ averages of the service period. In a French CR evaluation by Barbat et al. (2010), the applied repeatability animal model for multiple services included an interval from calving to insemination $\times$ parity effect. This effect also most likely accounted for a change in expectations and, thus, ensured unbiased genetic trends. Moreover, the authors first fitted a univariate model and, based on the results, pre-corrected all non-genetic effects before using the adjusted records for multivariate genetic analysis. In the analyses described by de Haer et al. (2013), no similar time-dependent effect was included, and instead, the authors analyzed averaged CR observations. Kuhn et al. (2006) assumed no effect of service number per se on $\mathrm{CR}$, except from a management point of view, but they did include the effect of service number in their model. VanRaden et al. (2014) also pre-adjusted the $\mathrm{CR}$ records for service number. The gradually decreasing CR with increasing service number observed in our study, as well as in the study by Boichard and Manfredi 
(1994), gives support to our results from the simulation study: The less successfully a female was served earlier in the service period, the smaller the probability to conceive from subsequent services.

\section{Estimated Variance Components}

Heritabilities. Heritability estimates for all fertility traits were generally low (Table 3 ), ranging from 0.01 (CR0 in HOL) to 0.07 (ICF3 in HOL). Low estimates could be expected, as the effect of the environment on these traits is considerable; hence, it may be difficult to accurately estimate the genetic component in the phenotypic variation (Wall et al., 2003; Berry et al., 2014).

The estimated heritabilities for interval traits in our study were either similar to or higher than those reported in the literature (Pryce and Veerkamp, 2001; Liu et al., 2008; Berry et al., 2014). Berry et al. (2014) observed large variability in ICF heritability: in their review, the estimates ranged from 0.02 to 0.11 , with means of 0.05 (HOL) and 0.04 (other breeds). These are close to our results, whereas Liu et al. (2017) reported higher values for ICF1 and ICF2 (0.10 and 0.08) and the same value as ours for ICF3.

The heritabilities for IFL traits in our study were on a similar level as those estimated previously (0.01 to 0.07 ) in cows across parities (Pryce and Veerkamp, 2001; Liu et al., 2008; Berry et al., 2014). In heifers, our heritability estimate for IFL0 in HOL was in agreement with earlier studies (Liu et al., 2008; Gredler and Schnyder 2013; de Haer et al., 2013; Liu et al., 2017), whereas our estimate for IFL0 in RDC was slightly higher. Consistent with the literature, the heritabilities for IFL were lower than for ICF (Pryce and Veerkamp, 2001; Liu et al., 2008; Berry et al., 2014).

Our heritability estimates for CR traits ranged from 0.017 to 0.030 , which is consistent with the results of other studies (Boichard and Manfredi, 1994; Aguilar

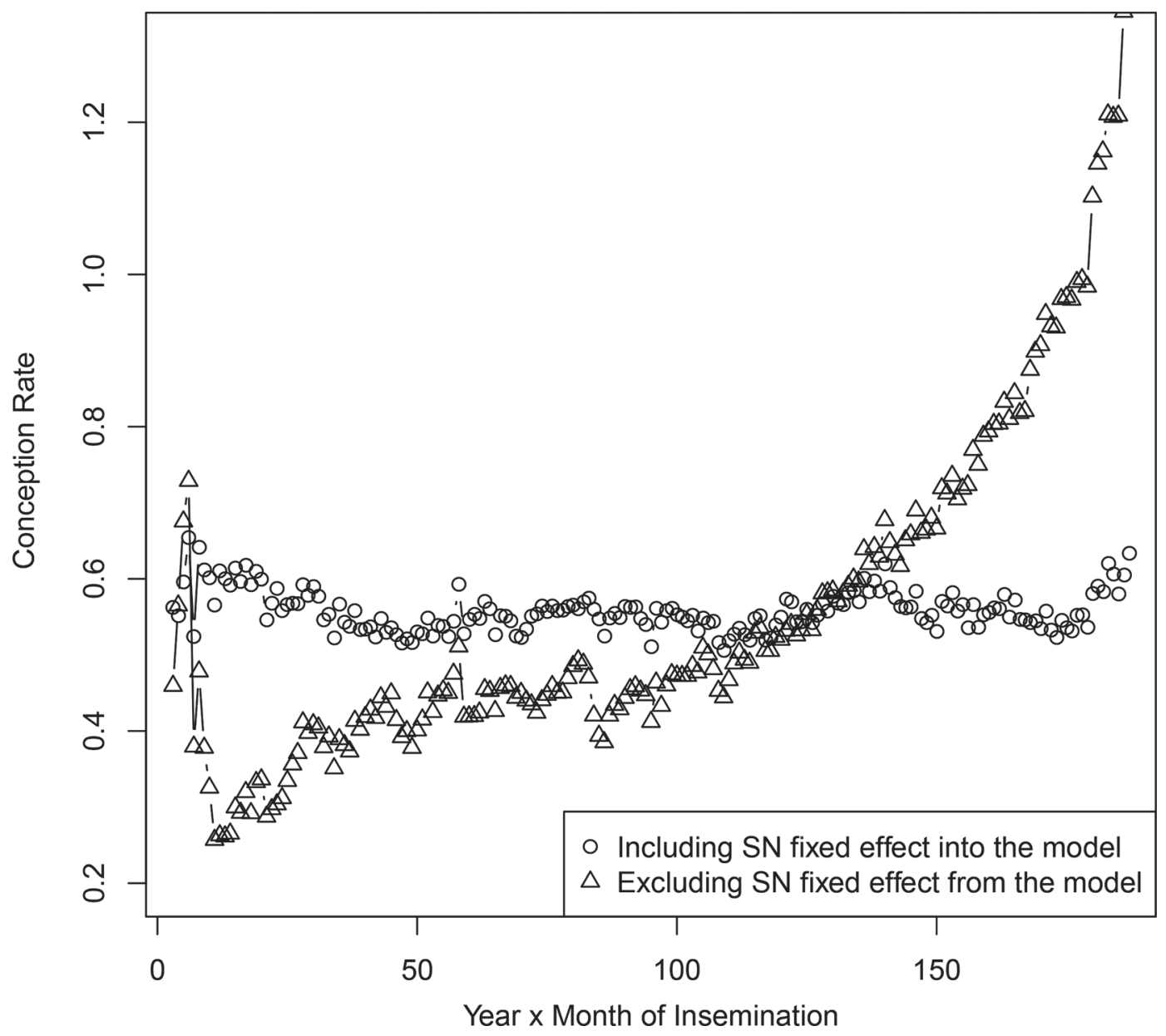

Figure 1. Estimated environmental effects for conception rate based on simulated data replicate 4, with and without the fixed effect of service number $(\mathrm{SN})$ in the model, by insemination year $\times$ month classes. 
Table 3. Heritabilities $\left(h^{2}\right)$ with standard errors $(S E)$ and significance levels for fertility traits in Nordic Holstein (HOL) and Nordic Red Dairy Cattle (RDC)

\begin{tabular}{lll}
\hline Trait $^{1}$ & HOL & \multicolumn{1}{c}{ RDC } \\
\hline ICF1 & $0.057 \pm 0.011^{* * *}$ & $0.049 \pm 0.011^{* * *}$ \\
ICF2 & $0.055 \pm 0.010^{* * *}$ & $0.025 \pm 0.009^{* * *}$ \\
ICF3 & $0.067 \pm 0.012^{* * *}$ & $0.032 \pm 0.012^{* * *}$ \\
IFL0 & $0.012 \pm 0.005^{*}$ & $0.020 \pm 0.007^{* *}$ \\
IFL1 & $0.041 \pm 0.007^{* * *}$ & $0.024 \pm 0.008^{* *}$ \\
IFL2 & $0.048 \pm 0.010^{* * *}$ & $0.037 \pm 0.009^{* * *}$ \\
IFL3 & $0.047 \pm 0.012^{* * *}$ & $0.041 \pm 0.013^{* *}$ \\
CR0 & $0.008 \pm 0.003^{* *}$ & $0.017 \pm 0.006^{* *}$ \\
CR1 & $0.025 \pm 0.006^{* * *}$ & $0.017 \pm 0.007^{*}$ \\
CR2 & $0.030 \pm 0.007^{* * *}$ & $0.021 \pm 0.006^{* * *}$ \\
CR3 & $0.029 \pm 0.008^{* * *}$ & $0.024 \pm 0.009^{* *}$ \\
\hline
\end{tabular}

${ }^{1}$ Traits: ICF $=$ interval from calving to first parity, IFL $=$ interval from first to last service, $\mathrm{CR}=$ conception rate: $0=$ heifers, $1=$ first, $2=$ second, and $3=$ third parity.

${ }^{*} P<0.05,{ }^{* *} P<0.01,{ }^{* * *} P<0.001 ;$ where $P=\exp \left(-0.717 z-0.416 z^{2}\right)$, with $z=\frac{h^{2}}{S E}$. et al., 2011; de Haer et al., 2013). In the Netherlands, de Haer et al. (2013) reported heritability estimates similar to ours for CR (0.003 to 0.033), despite the different trait definition and differences in the phenotypic means. As in our study, their heritability estimates for $\mathrm{CR}$ were lower in heifers than in cows.

Coefficient of Genetic Variation. The low levels of heritability values may, per se, lead to underestimation of the genetic potential in fertility traits. The coefficient of genetic variation $(\mathbf{C V g}$; i.e., the genetic standard deviation as a percentage of the phenotypic mean) shows that exploitable genetic variation does exist in these traits. For ICF, the estimated CVg was $8 \%$ in the first and second parities, and $9 \%$ in the third parity. These results are within the range of estimates (3 to 11\%) in the meta-analyses by Pryce and Veerkamp (2001) and by Berry et al. (2014). A value of $36 \%$ has also been reported (Kadarmideen et al., 2000). For IFL, the CVg was $22 \%$ in heifers, $28 \%$ in primiparous cows, and $27 \%$ in multiparous cows. These results are

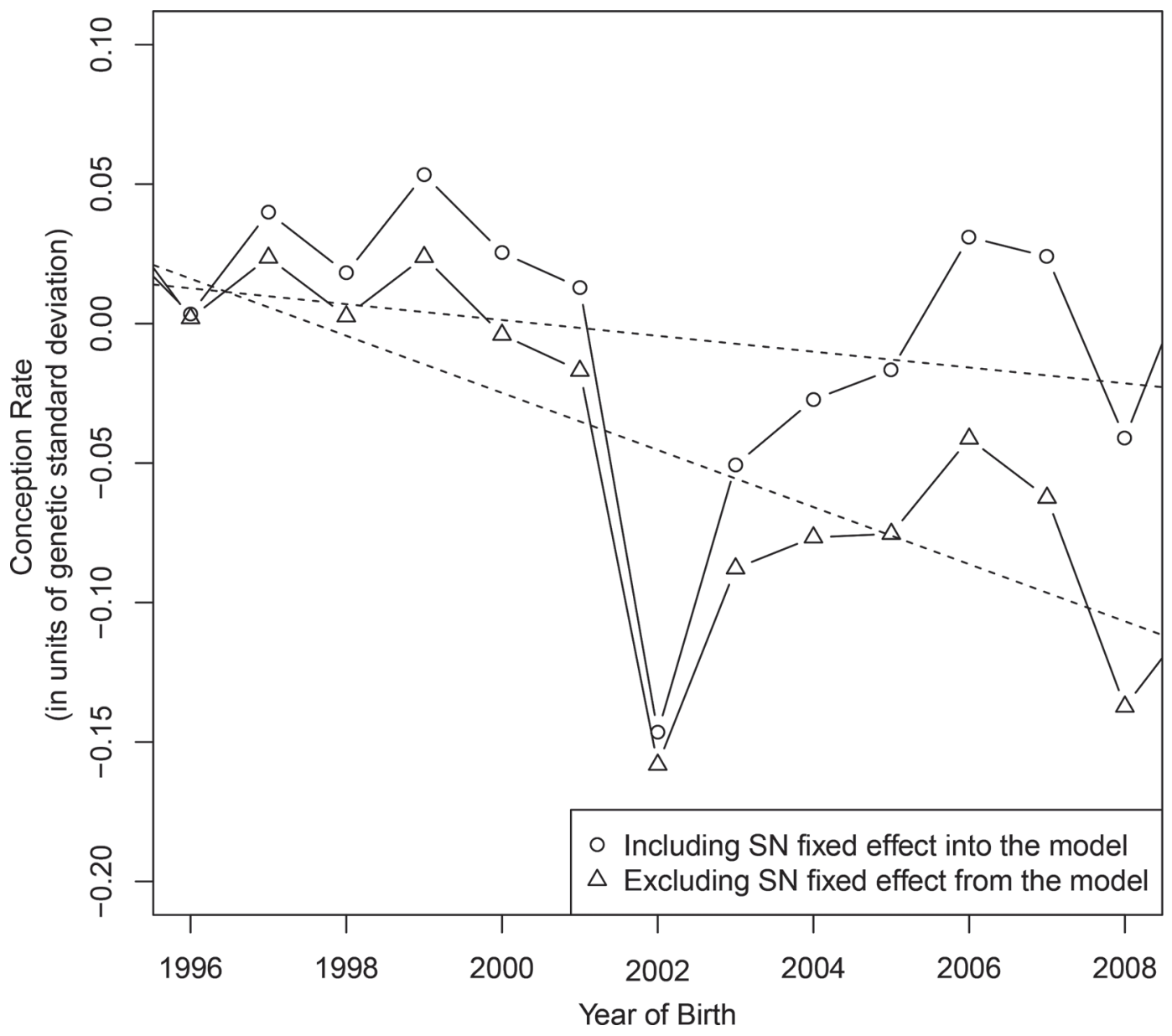

Figure 2. Estimated genetic trend for conception rate in cows based on simulated data replicate 4, with and without the fixed effect of service number (SN) in the model, by birth year classes. 
consistent with the range, 17 to $30 \%$, reviewed by Pryce and Veerkamp (2001). For CR, the CVg was $6 \%$ in heifers, $17 \%$ in primiparous cows, and $21 \%$ in multiparous cows. Boichard and Manfredi (1994) obtained a CVg estimate of $14 \%$ for CR. However, it has been debated whether a $\mathrm{CVg}$ exists for $\mathrm{CR}$, as the mean and variance may be inseparable (Kadarmideen et al., 2000).

The CVg estimates for fertility traits are on a similar or higher level compared with those found for milk production traits, which are between 9 and 10\% (M. Lidauer, Natural Resources Institute Finland, Jokioinen, Finland; personal communication). Combined with the information on $\mathrm{CVg}$, our results suggest that exploitable genetic variation does indeed exist for selection in the fertility traits of both heifers and cows, despite the fact that the heritabilities per se were low.

Genetic Correlations Within Fertility Traits Across Parities. Within-trait genetic correlations were positive and ranged from moderate to high (Tables 4 and 5). The highest correlations occurred between cow traits (close to 0.9 between all traits), whereas correlations between heifer and cow traits were moderate (0.4 to 0.7). Genetic correlations between heifer and first-parity cow traits were higher than between heifer and later-parity cow traits.

Analysis revealed moderate correlations between heifer and cow traits in both breeds. Correlations between heifer and cow IFL (0.39 to 0.67$)$ were within the range reported in earlier studies (Roxström et al., 2001; Liu et al., 2008; Liu et al., 2017). In the literature, a certain fertility trait in cows in different parities has commonly been considered to represent the same trait, which has increased the variability reported within the trait (e.g., Tiezzi et al., 2012; Gredler and Schnyder, 2013).

Genetic correlations between heifer and cow CR in our study were on a similar level (0.43 to 0.72$)$ to those reported by Barbat et al. (2010) in HOL. Kuhn et al. (2006), however, found a lower correlation between first-service CR in heifers and cows (0.39), as did Liu et al. (2017), who reported estimates from 0.25 to 0.45 . The fact that both of these analyses were restricted to first-service CR may have affected the range of the correlations.

The moderate correlations observed between heifer and cow traits indicate that genetic control of heifer and cow fertility differs somewhat (Pryce et al., 2004; Liu et al., 2008; de Haer et al., 2013). This is not surprising, because cows have a greater metabolic load and need resources for recovery from pregnancy and for peak lactation (Pryce et al., 2004; Walsh et al., 2011; Tiezzi et al., 2012). Still, the magnitude of genetic correlation implies that selection for heifer fertility also affects cow fertility, and the other way around. Inclusion of

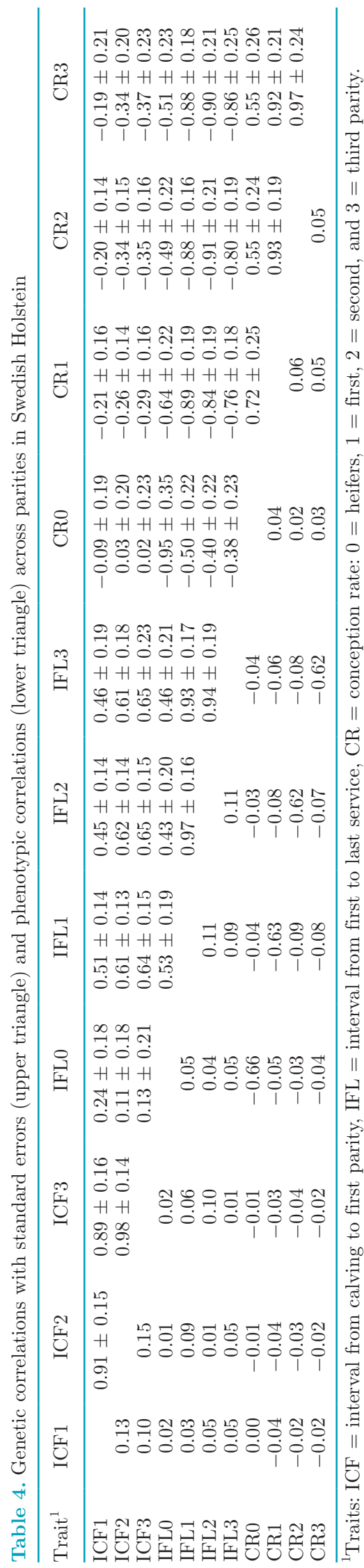




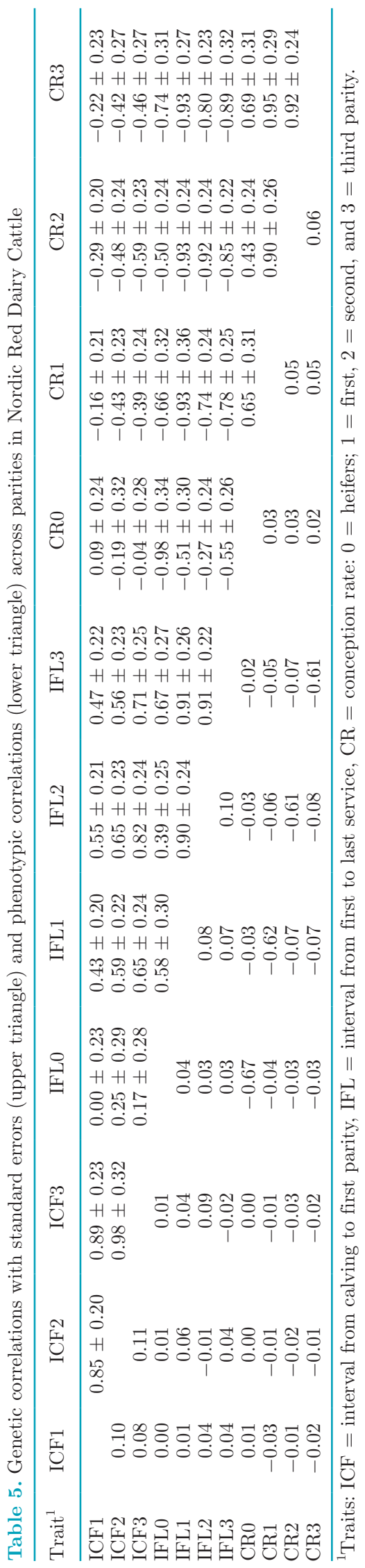

both heifer and cow traits in the evaluation model will enhance the genetic gain in total fertility and enable a more accurate evaluation, as the information on heifers is available at an early stage of life. Records show that cow fertility in Nordic countries has deteriorated more than heifer fertility and, hence, requires more emphasis in breeding schemes.

All within-trait correlations were high in cow traits in both breeds. ICF correlations varied between 0.85 and 0.98 , with $\mathrm{RDC}$ at the lower end of the range. Roxström et al. (2001) reported more variation in the Swedish Red and White breed (from 0.8 to unity). Our estimates for IFL were also high, from 0.85 to 0.97 , and on a similar level to those observed in Swedish Red and White (0.9; Roxström et al., 2001) and Brown Swiss (0.96; Tiezzi et al., 2012). In a more recent study, Liu et al. (2017) found IFL correlations from 0.91 to 0.96 for the first 3 parities.

For CR, correlations between cow parities in both breeds ranged from 0.90 to 0.97 . These correlations are similar to those obtained by Aguilar et al. (2011), whereas Liu et al. (2017) reported unity correlations between parities 1 and 2 but correlations of 0.6 between parities 1 and 3 , and 2 and 3 .

It can be questioned whether later parities should be treated as the same trait by including parity as a fixed effect in the evaluation model, as was done for first-service CR by Oltenacu et al. (1991) and for the interval traits by Tiezzi et al. (2012). In our study, correlations across parities did not reach unity, and so traits in different parities can be considered as genetically separate, although highly correlated, traits. However, the use of such models requires a sufficiently large data size to allow estimation of breeding values in separate parities, as is the case in the Nordic fertility evaluation. Aguilar et al. (2011) and de Haer et al. (2010) followed the same strategy, and Liu et al. (2017) suggested keeping at least heifers and first parity separate from later parities. Separate evaluation of parities implies the assumption that fertility in different parities is affected by different factors. Each breeding event and service period contains detailed information behind the records, and traits with low heritability benefit from a detailed model to better capture genetic variation. Further, this strategy makes it possible to build a fertility index that gives different weights to different parities relative to the frequency of observations analogously to the other NAV routine evaluations (NAV Nordic Cattle Genetic Evaluation, 2019).

Genetic Correlations Across Traits. The correlations below are presented in the following order: correlations between heifer traits, between cow traits, and between heifer and cow traits (Tables 4 and 5). 
The genetic correlation between IFL0 and CR0 was high and negative in both breeds $(-0.95$ and -0.98$)$. This correlation was slightly stronger than the one found between IFL0 and first-service CR0 $(-0.86)$ in the study by Liu et al. (2017). A negative correlation is biologically favorable, as a short IFL period is linked to a CR value of 1 .

Within-parity correlations between the interval traits (ICF and IFL) in cows were positive and moderate, ranging from 0.43 (first parity in RDC) to 0.71 (third parity in RDC). With the exception of the first-parity correlation (0.51 in HOL), the estimates were higher in RDC than in HOL. Across-parity correlations between interval traits were lower, from 0.45 to 0.65 in HOL and from 0.43 to 0.82 in RDC, but still higher than those (0.30 to 0.44$)$ estimated by de Haer et al. (2010). Liu et al. (2008) reported a correlation of similar magnitude, and Liu et al. (2017) a correlation of 0.48 for pooled parities. The moderate positive genetic correlations suggest that cows with genetically short ICF also have better breeding values for IFL.

Within-parity correlations between ICF and CR in cows ranged from -0.16 to -0.46 . Similar to interval traits, the first-parity correlation was lower in RDC than in HOL, but RDC had higher estimates than HOL in later parities. Across-parity correlations varied between -0.19 and -0.35 in HOL and between -0.22 and -0.59 in RDC. These correlations indicate that cows with better fertility have shorter ICF and higher CR. To our knowledge, no other studies have reported correlations between the interval traits and multiple-record CR by separate parities in cows, although Liu et al. (2017) estimated the correlation between first-service CR and ICF (-0.43) for pooled parities.

Within-parity correlations between IFL and CR in cows ranged from -0.86 (IFL3 and CR3 in HOL) to -0.93 (IFL1 and CR1 in RDC). Thus, they were in all cases lower than correlations between heifer IFL and $\mathrm{CR}$, which were close to unity. Although both traits describe the ability of the female to conceive and of the embryo to survive, IFL and CR do differ in their ability to show estrus. A silent or short unnoticed estrus is accounted for by a longer IFL value, but it does not result in a $\mathrm{CR}$ observation. Because heifers have better fertility with more intense estruses, close-to-unity genetic correlations between IFL0 and CR0 could be expected in both HOL and RDC heifers.

Genetic correlations between IFL0 and ICF were low but favorable ( 0.11 to 0.24 in HOL; 0.00 to 0.25 in $\mathrm{RDC})$. These results are consistent with the genetic correlation (0.17) between heifer IFL and cow ICF in the study by Liu et al. (2008). Genetic correlations for IFL0 with CR1, CR2, and CR3 ranged from -0.49 to
-0.74 in our study, whereas correlations for CR0 with IFL1, IFL2, and IFL3 were a bit lower, varying between -0.38 and -0.50 in HOL and between -0.27 and -0.55 in RDC. Correlations of similar magnitude were reported in Dutch HOL by de Haer et al. (2013). By and large, the magnitude of correlations between heifer and cow traits implies that a heifer's ability to conceive affects the length of the service period also in later parities, supporting the hypothesis of a fairly similar genetic background in heifers and cows.

Phenotypic Correlations. In general, all phenotypic correlations were biologically favorable, and their patterns in all parities and traits were in line with the genetic correlations (Tables 4 and 5). However, because the estimates were close to 0 , it is not possible to draw any deeper conclusions. The only notable exceptions were the within-parity phenotypic correlations between IFL and CR, which varied from -0.62 to -0.66 in $\mathrm{HOL}$ and from -0.61 to -0.67 in RDC. Our results are in agreement with those reported by Liu et al. (2017), who found a moderate negative phenotypic correlation of -0.58 between IFL0 and first-service CR0, and phenotypic correlations close to 0 among the other fertility traits.

\section{CONCLUSIONS}

In this study we estimated variance components for female fertility in the Nordic Holstein and Nordic Red Dairy Cattle breeds by multiple-trait REML. The applied method allowed the inclusion of 3 fertility traits for heifers and for the first 3 parities in cows in a multipletrait setup, yielding 11 correlated traits that were estimated simultaneously in the same analysis. Our results show that it is crucial to include a service number effect into the conception rate model, to account for changes in expectation of successful AI with increasing number of services. The obtained heritability estimates ranged from 0.01 to 0.07 , the lowest being for heifer traits in both breeds. In cows, the highest heritability estimates were for the interval from calving to first insemination in Nordic HOL, and the lowest for conception rate in Nordic RDC. The moderate genetic correlations found between heifer and cow traits provide support for the inclusion of both heifer and cow fertility traits into genetic evaluation schemes for dairy cattle.

\section{ACKNOWLEDGMENTS}

This study was part of a joint project to establish animal model genetic evaluations for female fertility in Nordic dairy cattle. The study was financed by Nordic Cattle Genetic Evaluation (NAV), Aarhus, Denmark, 
and by Natural Resources Institute Finland (Luke), Helsinki, Finland. Swedish data were provided through Nordic Cattle Genetic Evaluation (NAV), which is greatly acknowledged.

\section{REFERENCES}

Aguilar, I., I. Misztal, S. Tsuruta, G. R. Wiggans, and T. J. Lawlor. 2011. Multiple trait genomic evaluation of conception rate in Holsteins. J. Dairy Sci. 94:2621-2624. https://doi.org/10.3168/jds .2010-3893.

Andersen-Ranberg, I. M., B. Heringstad, D. Gianola, Y. M. Chang, and G. Klemetsdal. 2005. Comparison between bivariate models for 56-day nonreturn and interval from calving to first insemination in Norwegian Red. J. Dairy Sci. 88:2190-2198. https://doi .org/10.3168/jds.S0022-0302(05)72894-0.

Barbat, A., P. Le Mézec, V. Ducrocq, S. Mattalia, S. Fritz, D. Boichard, C. Ponsart, and P. Humblot. 2010. Female fertility in French dairy breeds: Current situation and strategies for improvement. J. Reprod. Dev. 56:S15-S21. https://doi.org/10.1262/jrd.1056S15.

Berry, D. P., E. Wall, and J. E. Pryce. 2014. Genetics and genomics of reproductive performance in dairy and beef cattle. Animal 8:105-121. https://doi.org/10.1017/S1751731114000743.

Boichard, D., A. Barbat, and M. Briend. 1998. Genetic evaluation for fertility in French dairy cattle. Interbull Bull. 18:99-101.

Boichard, D., and E. Manfredi. 1994. Genetic analysis of conception rate in French Holstein cattle. Acta Agric. Scand. A-An. 44:138 145. https://doi.org/10.1080/09064709409410890.

Chang, Y. M., I. M. Andersen-Ranberg, B. Heringstad, D. Gianola, and G. Klemetsdal. 2006. Bivariate analysis of number of services to conception and days open in Norwegian Red using a censored threshold-linear model. J. Dairy Sci. 89:772-778. https://doi.org/ 10.3168/jds.S0022-0302(06)72138-5.

de Haer, L. C. M., G. de Jong, M. L. van Pelt, and J. E. Roelfzema. 2010. Investigation of interval first to last insemination for dairy cattle in the Netherlands. Interbull Bull. 42:100-103.

de Haer, L. C. M., G. de Jong, and P. J. A. Vessies. 2013. Estimation of genetic parameters of fertility traits, for virgin heifers in the Netherlands. Interbull Bull. 47:142-146.

Fogh, A., A. Roth, O. M. Pedersen, J. Eriksson, J. Juga, M. Toivonen, I. M. A. Ranberg, T. Steine, U. S. Nielsen, and G. P. Aamand. 2003. A joint Nordic model for fertility traits. Interbull Bull. $31: 52-55$.

García-Cortés, L. A., C. Moreno, L. Varona, and J. Altarriba. 1992. Variance component estimation by resampling. J. Anim. Breed. Genet. 109:358-363.

Gianola, D. 1979. Heritability of polychotomous characters. Genetics 93:1051-1055.

Gredler, B., and U. Schnyder. 2013. New genetic evaluation of fertility in Swiss Brown Swiss. Interbull Bull. 47:226-229.

Hayes, J. F., and W. G. Hill. 1981. Modification of estimates of parameters in the construction of genetic selection indices ("Bending"). Biometrics 37:483-493.

ICAR. 2019. Milk yearly surveys. Accessed Jan. 25, 2019. http://www .icar.org/index.php/publications-technical-materials/milk-yearly -surveys-cow-sheep-goats/

Interbull. 2019a. National genetic evaluation forms provided by countries. Accessed Jan. 22, 2019. http://www.interbull.org/ib/ geforms.

Interbull. 2019b. Interbull code of practice: Traits and breeds. Accessed Apr. 9, 2019. http://www.interbull.org/ib/cop_chap6

Kadarmideen, H. N., R. Thompson, M. P. Coffey, and M. A. Kossaibati. 2003. Genetic parameters and evaluations from single- and multiple-trait analysis of dairy cow fertility and milk production. Livest. Prod. Sci. 81:183-195. https://doi.org/10.1016/S0301 -6226(02)00274-9.

Kadarmideen, H. N., R. Thompson, and G. Simm. 2000. Linear and threshold model genetic parameters for disease, fertility and milk production in dairy cattle. Anim. Sci. 71:411-419. https://doi.org/ 10.1017/S1357729800055338.

Koeck, A., C. Egger-Danner, C. Fuerst, W. Obritzhauser, and B. Fuerst-Waltl. 2010. Genetic analysis of reproductive disorders and their relationship to fertility and milk yield in Austrian Fleckvieh dual-purpose cows. J. Dairy Sci. 93:2185-2194. https://doi.org/10 $.3168 /$ jds.2009-2570.

Kuhn, M. T., J. L. Hutchinson, and G. R. Wiggans. 2006. Characterization of Holstein heifer fertility in the United States. J. Dairy Sci. 89:4907-4920. https://doi.org/10.3168/jds.S0022-0302(06)72541 $-3$.

Lidauer, M. H., J. Pösö, J. Pedersen, J. Lassen, P. Madsen, E. A. Mäntysaari, U. S. Nielsen, J.-Å. Eriksson, K. Johansson, T. Pitkänen, I. Strandén, and G. P. Aamand. 2015. Across-country test-day model evaluations for Holstein, Nordic Red Cattle, and Jersey. J. Dairy Sci. 98:1296-1309. https://doi.org/10.3168/jds.2014-8307.

Liu, A., M. S. Lund, Y. Wang, G. Guo, G. Dong, P. Madsen, and G. Su. 2017. Variance components of female fertility traits in Chinese Holstein population. J. Anim. Sci. Biotechnol. 8:56. https://doi .org/10.1186/s40104-017-0189-x.

Liu, Z., J. Jaitner, F. Reinhardt, E. Pasman, S. Rensing, and R. Reents. 2008. Genetic evaluation of fertility traits of dairy cattle using a multiple trait animal model. J. Dairy Sci. 91:4333-4343. https://doi.org/10.3168/jds.2008-1029.

Madsen, P., and J. Jensen. 2012. A user's guide to DMU. Version 6, release 5.1. Aarhus University, Faculty of Agricultural Sciences. Denmark. http://www.dmu.agrsci.dk/DMU/Doc/Previous/ dmuv6_guide.5.1.pdf

Matilainen, K., E. A. Mäntysaari, M. H. Lidauer, I. Strandén, and R. Thompson. 2012. Employing a Monte Carlo algorithm in expectation maximization restricted maximum likelihood estimation of the linear mixed model. J. Anim. Breed. Genet. 129:457-468. https://doi.org/10.1111/j.1439-0388.2012.01000.x.

Matilainen, K., R. Mrode, I. Strandén, R. Thompson, and E. A. Mäntysaari. 2009. Linear-threshold animal model for birth weight, gestation length and calving ease in United Kingdom Limousin beef cattle data. Livest. Sci. 122:143-148.

Matilainen, K., I. Strandén, G. P. Aamand, and E. A. Mäntysaari. 2018. Single step genomic evaluation for female fertility in Nordic Red dairy cattle. J. Anim. Breed. Genet. 135:337-348. https://doi .org/10.1111/jbg.12353.

MiX99 Development Team. 2017. MiX99: A software package for solving large mixed model equations. Natural Resources Institute Finland (Luke), Jokioinen, Finland. Accessed Jan. 22, 2019. http:// www.luke.fi/mix99

Muuttoranta, K., A.-M. Tyrisevä, E. A. Mäntysaari, J. Pösö, G. P. Aamand, J. Eriksson, U. S. Nielsen, and M. H. Lidauer. 2015. Genetic parameters for female fertility in Nordic dairy cattle. Interbull Bull. 49:32-35.

NAV Nordic Cattle Genetic Evaluation. 2019. NAV routine genetic evaluation of dairy cattle: Data and genetic models. 7th ed. Accessed Jun. 17, 2019. https://www.nordicebv.info/wp-content/ uploads/2019/06/NAV-routine-genetic-evaluation-04062019.pdf.

Norman, H. D., J. R. Wright, S. M. Hubbard, R. H. Miller, and J. L. Hutchison. 2009. Reproductive status of Holstein and Jersey cows in the United States. J. Dairy Sci. 92:3517-3528. https://doi.org/ 10.3168/jds.2008-1768.

Oltenacu, P. A., A. Frick, and B. Lindhé. 1991. Relationships of fertility to milk yield in Swedish cattle. J. Dairy Sci. 74:264-268. https: //doi.org/10.3168/jds.S0022-0302(91)78169-1.

Philipsson, J., and B. Lindhé. 2003. Experiences of including reproduction and health traits in Scandinavian dairy cattle breeding programmes. Livest. Prod. Sci. 83:99-112. https://doi.org/10.1016/ S0301-6226(03)00047-2.

Pritchard, T., M. Coffey, R. Mrode, and E. Wall. 2013. Genetic parameters for production, health, fertility and longevity traits in dairy cows. Animal 7:34-46. https://doi.org/10.1017/ S1751731112001401.

Pryce, J. E., M. D. Royal, P. C. Garnsworthy, and I. L. Mao. 2004. Fertility in the high-producing dairy cow. Livest. Prod. Sci. 86:125-135. https://doi.org/10.1016/S0301-6226(03)00145-3. 
Pryce, J. E., and R. F. Veerkamp. 2001. The incorporation of fertility indices in genetic improvement programmes. BSAS Occ. Publ., 26:237-250. Br. Soc. Anim. Sci., Penicuik, United Kingdom.

Roxström, A., E. Strandberg, B. Berglund, U. Emanuelson, and J. Philipsson. 2001. Genetic and environmental correlations among female fertility traits and milk production in different parities of Swedish Red and White Dairy Cattle. Acta Agric. Scand. A Anim. Sci. 51:7-14. https://doi.org/10.1080/090647001300004745.

Tiezzi, F., C. Maltecca, A. Cecchinato, M. Penasa, and G. Bittante. 2012. Genetic parameters for fertility of dairy heifers and cows at different parities and relationships with production traits in first lactation. J. Dairy Sci. 95:7355-7362. https://doi.org/10.3168/jds $.2012-5775$

Tiezzi, F., C. Maltecca, M. Penasa, A. Cecchinato, Y. M. Chang, and G. Bittante. 2011. Genetic analysis of fertility in the Italian Brown Swiss population using different model and trait definitions. J. Dairy Sci. 94:6162-6172. https://doi.org/10.3168/jds.2011-4661.

Tyrisevä, A.-M., K. Muuttoranta, J. Pösö, U. S. Nielsen, J.-Å. Eriksson, G. P. Aamand, E. A. Mäntysaari, and M. H. Lidauer. 2017.
Evaluation of conception rate in Nordic dairy cattle. Interbull Bull. 51:32-35.

VanRaden, P. M., M. E. Tooker, J. R. Wright, C. Sun, and J. L. Hutchinson. 2014. Comparison of single-trait to multi-trait national evaluations for yield, health, and fertility. J. Dairy Sci. 97:79527962. https://doi.org/10.3168/jds.2014-8489.

Wall, E., S. Brotherstone, J. A. Woolliams, G. Banos, and M. P. Coffey. 2003. Genetic evaluation of fertility using direct and correlated traits. J. Dairy Sci. 86:4093-4102. https://doi.org/10.3168/ jds.S0022-0302(03)74023-5.

Walsh, S. W., E. J. Williams, and A. C. O. Evans. 2011. A review of the causes of poor fertility in high milk producing dairy cows. Anim. Reprod. Sci. 123:127-138.

Wathes, D. C., G. E. Pollott, K. F. Johnson, H. Richardson, and J. S. Cooke. 2014. Heifer fertility and carry over consequences for life time production in dairy and beef cattle. Animal 8:91-104. https: //doi.org/10.1017/S1751731114000755. 